\title{
HISTORICAL DEVELOPMENT OF COMPUTER-AIDED DESIGN (CAD) AND ITS APPLICATION IN EDUCATION AT FACULTY OF MECHANICAL ENGINEERING IN BELGRADE
}

\author{
Ivana Cvetković1, *, \\ Branislav Popkonstantinović1, \\ Dragan Cvetković2, \\ Miša Stojićević ${ }^{1}$, \\ Rodoljub Milićević ${ }^{1}$ \\ ${ }^{1}$ Faculty of Mechanical Engineering, \\ University of Belgrade, \\ Belgrade, Serbia \\ ${ }^{2}$ Singidunum University, \\ Belgrade, Serbia
}

Correspondence:

Ivana Cvetković

e-mail:

ivanacvetkovic1992@gmail.com

\begin{abstract}
:
Since its appearance in the middle of 20th century, Computer-Aided Design (CAD) has been constantly developing. The man who is considered to be the father of CAD and pioneer of computer graphics is Ivan Sutherland, American electrical engineer and computer scientist. Nowadays, it is almost impossible to imagine the industry without programs for modeling, drawing, simulation. They simplified the process of production and at the same time, shortened the time needed to display the final product. The first part of this paper deals with the evolution of computer graphics and its application in general. The second part of the paper is dedicated to the application of SolidWorks, as a CAD program, in education at the Faculty of Mechanical Engineering in Belgrade.
\end{abstract}

Keywords:

Computer-Aided Design, Education, Mechanical Engineering, SolidWorks, Ivan Sutherland.

\section{DEVELOPMENT OF COMPUTER - AIDED DESIGN (CAD)}

The first commercial numerical control software package named PRONTO (Programme for Numerical Tooling Operations) was written in 1957 by Dr. Patrick J. Hanratty, an American computer scientist, who worked for General Electric at that time [1, 2,3].

Although Hanratty was the first one who started working on the idea of computer graphics for design, the father of CAD is usually considered Dr. Ivan Sutherland (born in 1938). After high school, Sutherland enrolled Carnegie Institute of Technology (now Carnegie Mellon University) willing to study Electrical Engineering. Later on he moved to the University of California (Caltech), where he did his Master's Degree in Electrical Engineering. Eventually, he entered MIT where he started his $\mathrm{PhD}$ studies under the supervision of Claude Shannon (1916 - 2001), the inventor of information theory. Information theory studies the quantification, storage and communication of information and its discovery had a deep impact on the development of Internet, invention of compact disc, the success of the Voyager program (American scientific program made for study of outer Solar System) [1, 3]. 
The title of Sutherland's doctoral dissertation was "Sketchpad: A Man-Machine Graphical Communication System" and it was written in 1963. For his work, Sutherland received the Turing Award in 1988 and Kyoto Prize in 2012. Sketchpad was the first program that contained a graphical user interface (GUI). By using a light pen, users were able to draw directly on the CRT (cathode-ray tube) screen and that was the first time that engineering drawings could be drawn directly on a computer display. Sketchpad was developed and run on the TX-2 (computer built by Wesley Clark), one of the first programmable computers, within the MIT's Lincoln Laboratory. The light pen that was used for Sketchpad, was actually invented for the SAGE (Semiautomatic Ground Environment) air defense project. Commercial use of CAD programs started in 1970s [1, 3].

In 1977 Avions Marcel Dessault started the development of a 3D CAD program called CATI. The company was the property of Marcel Bloch (after World War II he changed his name to Marcel Dessault), who dedicated his life to aircraft manufacturing. In 1981, Avions Marcel Dessault created Dassault Systèmes in order to develop and market 3D CAD software CATIA V1 (first commercial version of CATI) $[1,3,4]$.

Over the years, CATIA started getting noticed in other sectors outside of aeronautical design, notably in the automotive industry, machinery, shipbuilding [4]. In 1997 Dassault Systèmes acquired SolidWorks Corporation (which was founded in 1993 by John Hirschtick).

Software package SolidWorks is a solid modeling $\mathrm{CAD} / \mathrm{CAE}$ program that runs on Microsoft Windows and it is learned at the Faculty of Mechanical Engineering in Belgrade.

\section{AESTHETICS OF PRODUCT AS A COURSE AT FACULTY OF MECHANICAL ENGINEERING}

Course called Aesthetics of Product belongs to Master Academic Studies at Faculty of Mechanical Engineering in Belgrade and it is mandatory for students of Department for Theory of Mechanisms and Machines. It covers principles of aesthetics in the process of product design, geometric harmony laws and advanced modeling in software package SolidWorks. As it is previously mentioned, SolidWorks is a CAD program that runs on Microsoft Windows and it is produced by a company named Dassault Systèmes.
Basics of modeling and drawing in SolidWorks is taught on the first year of Bachelor Academic Studies through the mandatory course named Engineering Graphics. This software package is elected due to its user-friendly interface. Throughout the years it has been proved that SolidWorks is the best choice for beginners. In order to improve their knowledge in the field of modeling, students are allowed to choose some courses dedicated to advance modeling later on.

The biggest part of the course Aesthetics of Product is dedicated to the SolidWorks feature called Surfaces. Surface body is a general term that describes connected zero-thickness geometries such as single surfaces, knit surfaces, trimmed and filleted surfaces [5]. This SolidWorks feature allows students to create different shapes easier than using regular features.

This software package enables students to define the shape of models in such way that models are more artistic [6]. It includes organic forms, complex geometry with complete control of their parameters. By using simulation tools, students can generate photorealistic images. As it is written before, SolidWorks has userfriendly and intuitive interface that allows its users to learn quickly all necessary commands so they can start creating their own items.

Considering the fact that all CAD programs are based on principles of Descriptive Geometry, students should learn its fundamentals firstly. In the first semester of the first year of bachelor studies, freshmen attend the mandatory course called Constructive Geometry and Graphics, where they acquire information about the basics of Descriptive Geometry. Their knowledge obtained during the previously mentioned course is applicable in every field of engineering, especially in the field of modeling.

The pyramid on a plane, conical sections, section of a cone and a plane and hyperboloid of one sheer that had been drawn manually during the course named Constructive Geometry and Graphics, afterwards are done in SolidWorks and shown in Figures 1, 2, 3 and 4.

Some items made by Surface feature, such as helmet, teapot, candlestick and bottle are shown in Figures 5, 6, 7 and 8. 


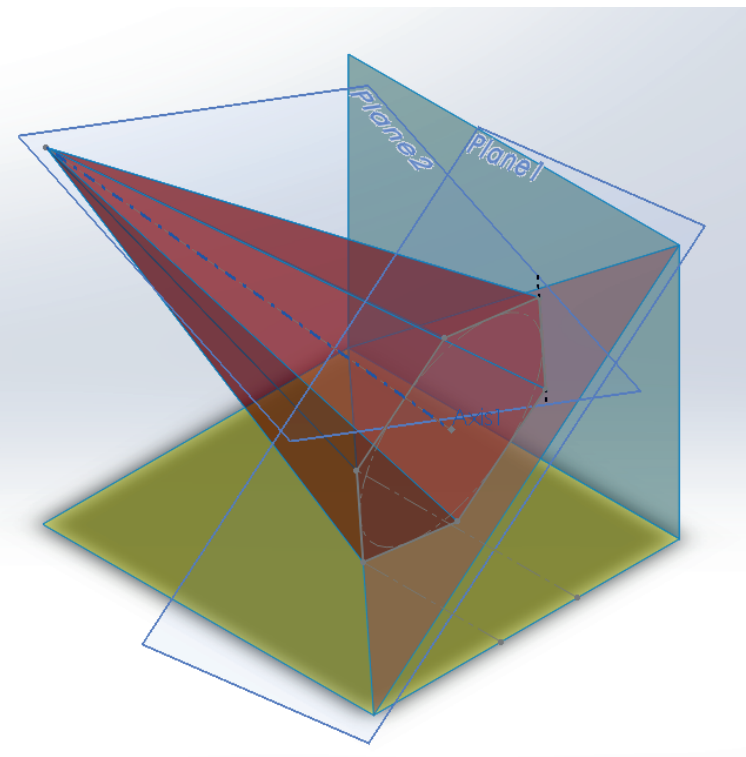

Fig. 1. Pyramid on a plane

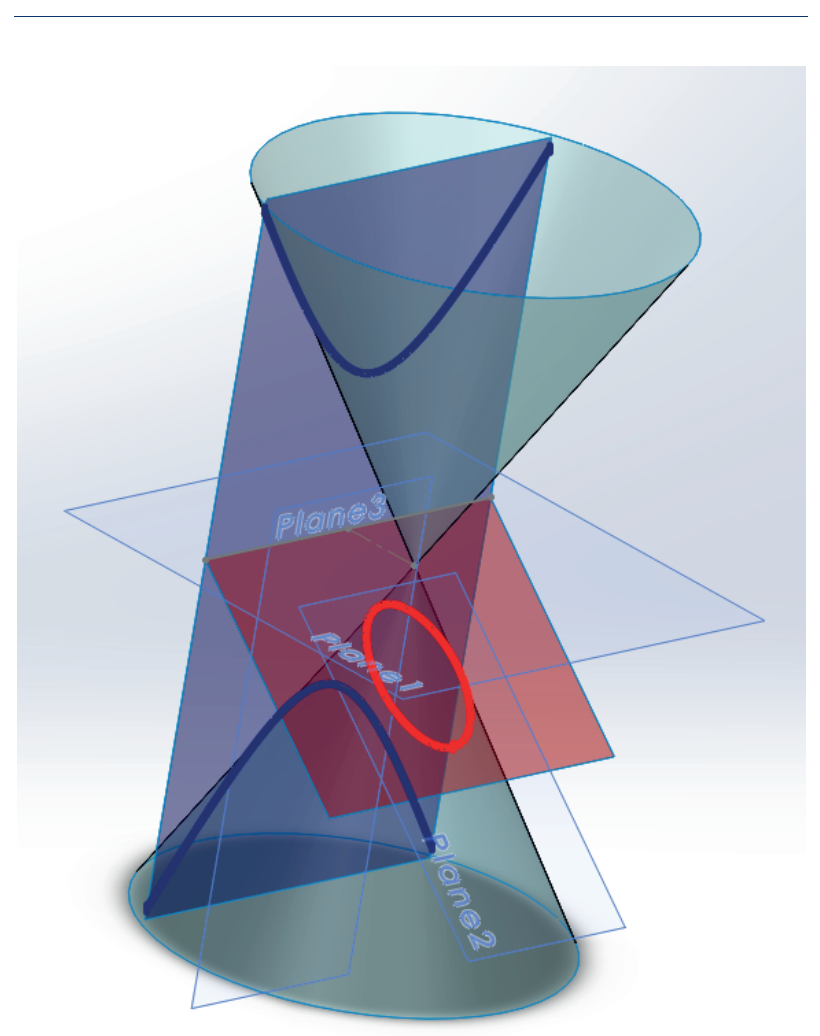

Fig. 2. Conical sections

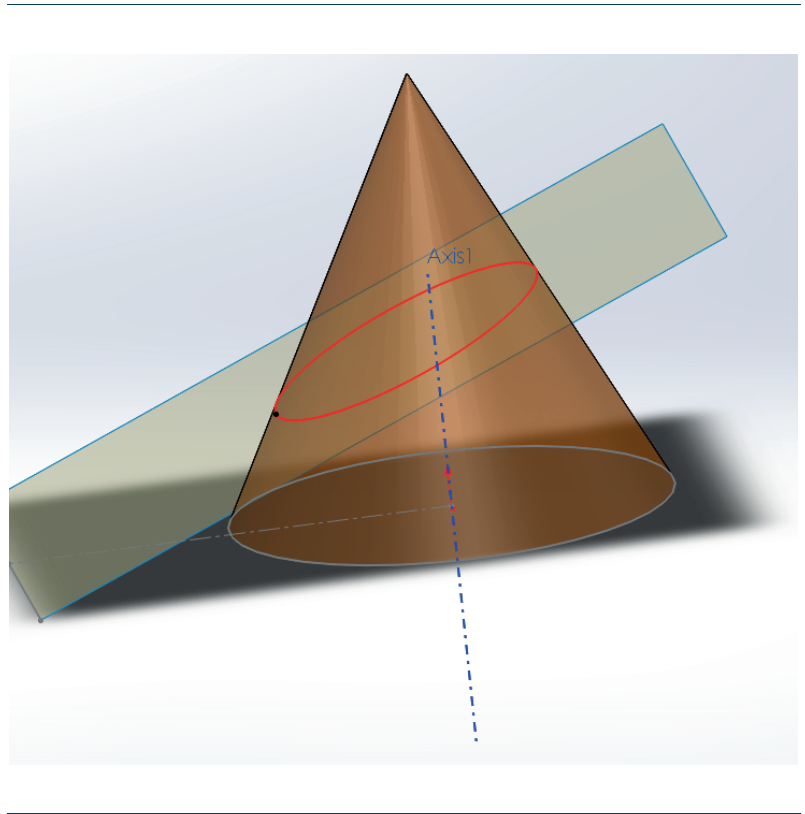

Fig. 3. Section of a cone and a plane

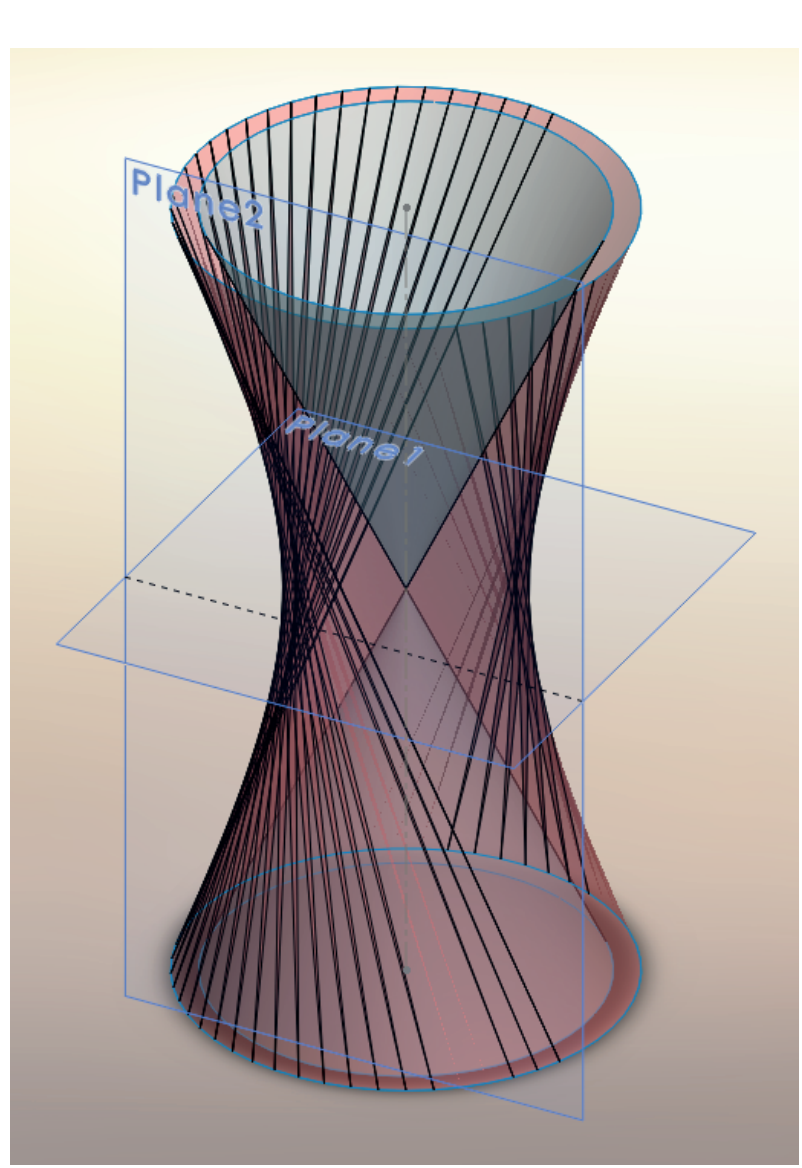

Fig. 4. Hyperboloid of one sheet 


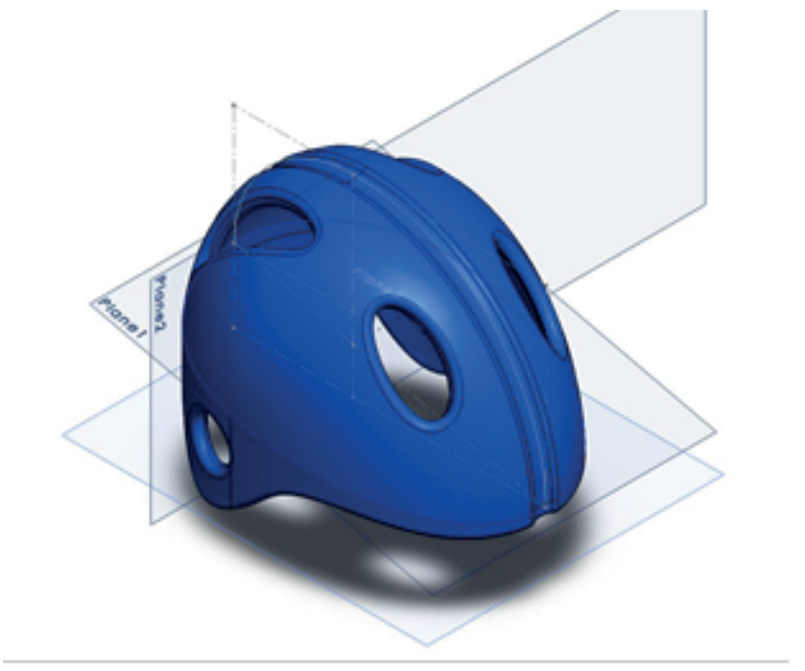

Fig. 5. Helmet

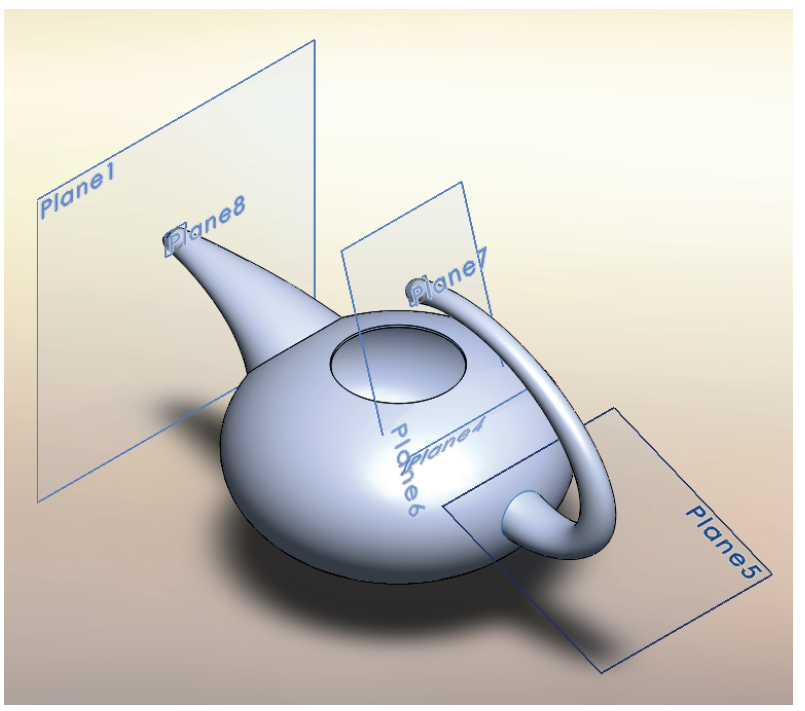

Fig. 6. Teapot

Astronomical clock that has been made by combining modeling, knowledge in the field of mechanics and Simulation tool in Solidworks is shown in Figure 9.

Thomas Earnshaw's chronometer detent escapement mechanism is shown in Figure 10. It represents marine chronometer that was simplified and modified by Thomas Earnshaw, English renowned watchmaker, in order to make it available to the public.

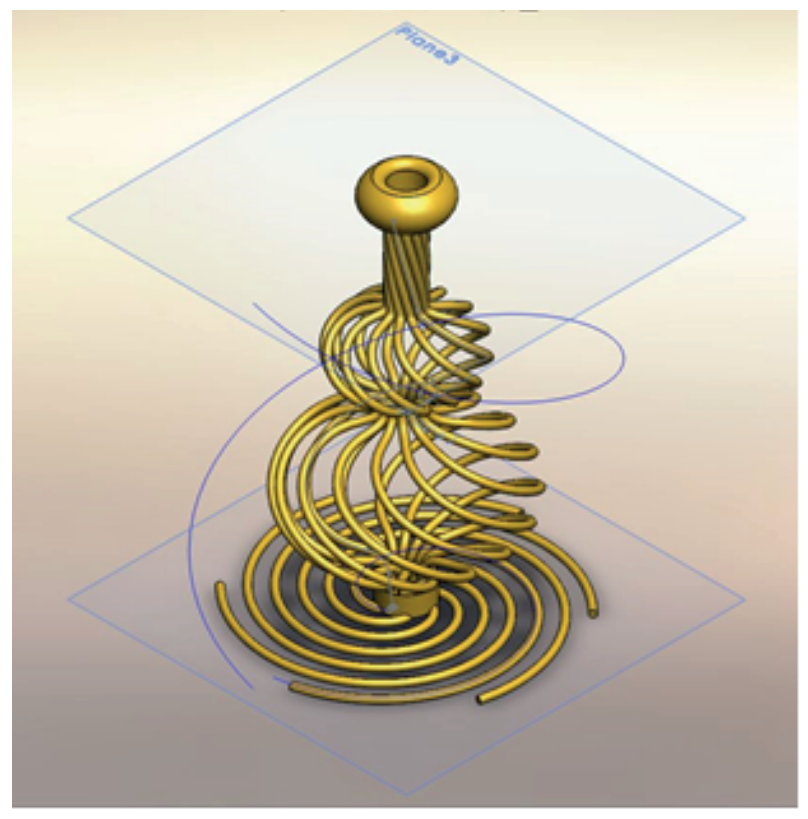

Fig. 7. Candlestick

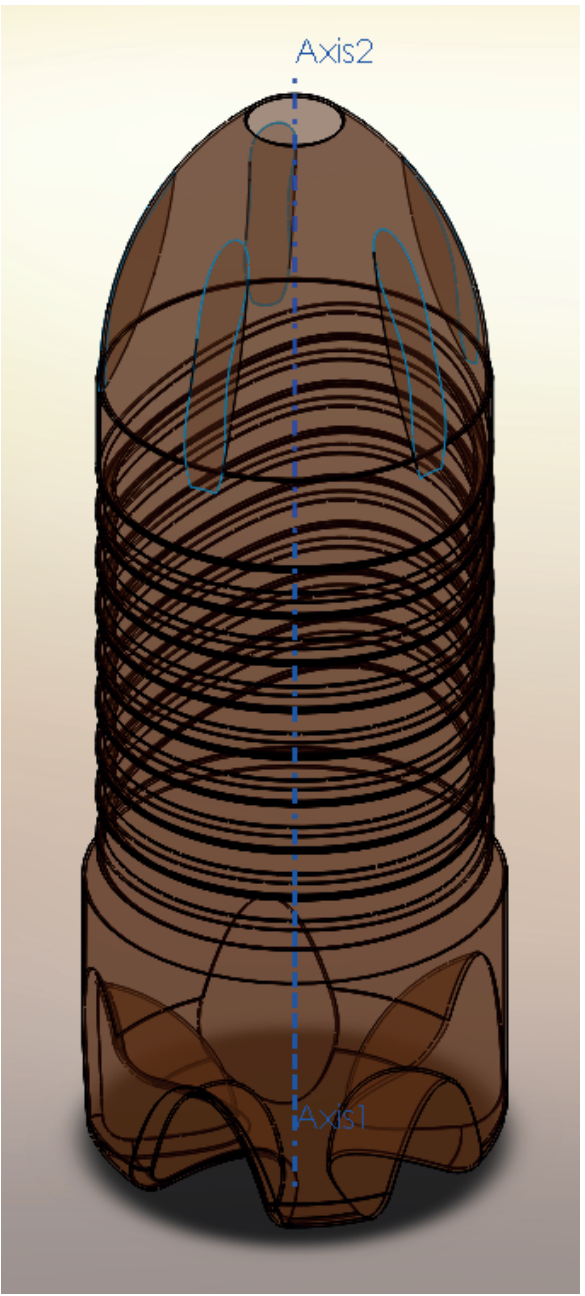

Fig. 8. Bottle 


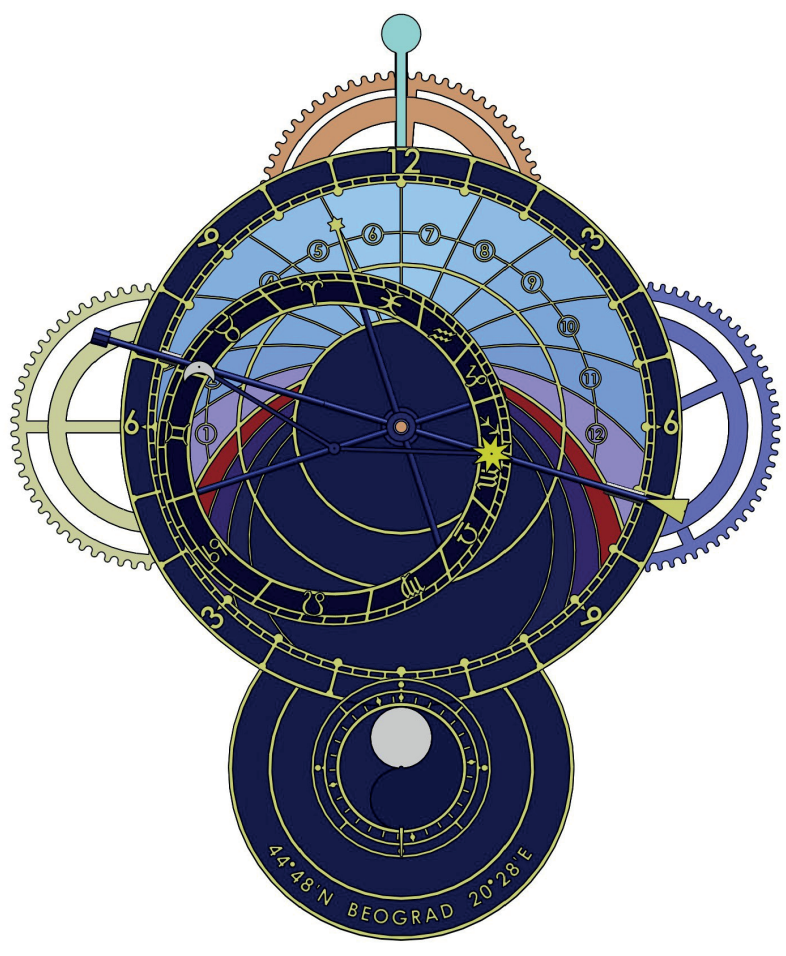

Fig. 9. Astronomical clock

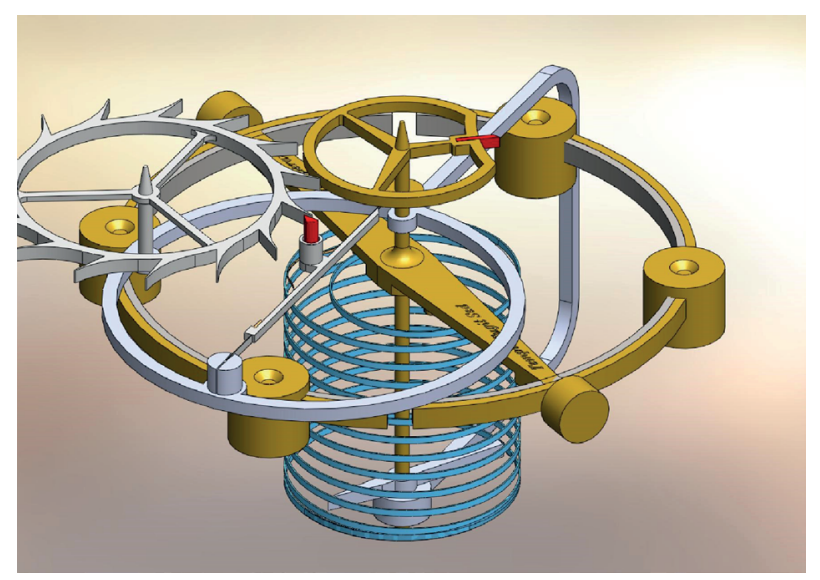

Fig. 10. Thomas Earnshaw's Chronometer Detent Escapement Mechanism
Considering the fact that the subject of this paper was the usage of $\mathrm{CAD}$ programs in education, universal principles of Aesthetics are completely neglected, but that does not mean that they are not important. On the contrary, they are crucial for every future engineer who wants to comprehend demands given by product designers. Through theoretical and practical exercises, students are provided by knowledge that can help them create a product in SolidWorks and implement learned design principles into their future work.

\section{ACKNOWLEDGMENT}

The research was performed in the frame of the national project TR 35022 financed by Ministry of Science of the Republic of the Serbia.

\section{REFERENCES}

[1] D. E. Weisberg, The Engineering Design Revolution, e-book, 2008

[2] J. Peddie, The History of Visual Magic in Computers: How Beautiful Images Are Made in CAD, 3D, VR and AR, Springer, 2013

[3] S. Tornincasa and F. Di Monaco, The Future and the Evolution of CAD, Proceedings of $14^{\text {th }}$ International Research/Conference "Trends in the Development of Machinery and Associated Technology", TMT, Mediterranean Cruise, pp. II-1 - II-18, September 2010

[4] https://www.linformaticien.com/dossiers/les-sagade-lit/id/20905/dassault-systemes-l-histoire-d-unereussite-unique.aspx (28.03.2019.)

[5] S. Tickoo, SOLIDWORKS 2018 for Designers, $16^{\text {th }}$ Edition, CAD/CIM Technologies, 2018

[6] S. Krasic, N. Ando, P. Pejatovic, Teaching of Geometric Surfaces for Architectural Students at the Faculty of Engineering and Design, of Hosei University in Tokyo, Japan, FME Transactions, Vol. 47, No.1, pp/ 293-298, 2019

\section{CONCLUSION}

Aesthetics of Product represents the course which enables students to apply their previously acquired skills on modeling of desired item. Since the students have gone through the mandatory courses named Constructive Geometry and Graphics and Engineering Graphics and dealt with the basics of Descriptive Geometry, they are able to continue with advanced modeling. 